4. Холщевников В.В. Проблемы оценки безопасности людей при пожаре в уникальных зданиях и сооружениях / В.В. Холщевников // Пожаровзрывобезопасность : сб. науч. тр. - 2003. - № 4. - C. $21-27$.

5. Самошин Д.А. Расчет пожарных рисков для общественных, жилых и административных зданий / Д.А. Самошин. - 46 c. [Электронный ресурс]. - Доступный c http://www.akademygps.ru. 6. Брушлинский Н.Н. Математическая модель для проектирования системы противопожарной защиты города / Н.Н. Брушлинский, Н.Н. Соболев // Управление большим городом : сб. науч. тр. - М. : НПО АСУ "Москва", 1985. - С. 79-81.

7. Carter G. Simulation model of fire department operation: design and preliminary results / G. Carter, I. Chaiken, E. Ignall // IEEE Transportation System Science and Cybernetics. - 1970 - № 40. Pp. 282-293.

8. Мушик Э. Методы принятия технических решений : пер. с нем. / Э. Мушик, П. Мюллер. М. : Изд-во "Мир", 1990. - 208 с.

9. Кіндрацький Б.І. Раціональне проектування машинобудівних конструкцій /

10. Нормативи по пожежно-стройовій підготовці. - К. : Вид-во УДПО МВС України, 1995 $14 \mathrm{c}$.

11. Мовчан I.О. Вибір критеріїв для прийняття рішень в системі пожежогасіння / I.О. Мовчан, М.I. Васильєв // Вісник Львівського державного університету безпеки . 146-154.

12. Бут В.П. Практичний посібник 3 пожежної тактики / В.П. Бут, .В. Куціщий, Б.В. Болібрух - Львів : Вид-во СПОЛОМ, 2003 - 133

$\begin{array}{llll}\text { 13. ДБН } & \text { В.2.5-56:2015 Системи протипожежного захисту. - К. : Міністерство }\end{array}$ регіонального розвитку, будівництва та житлово-комунального господарства України, 2014. $185 \mathrm{c}$

14. Гуліда Е.М. Методика визначення соціального пожежного ризику в приміщення навчальних закладів / Е.М. Гуліда, І.О. Мовчан, Т.М. Кіт // Науковий вісник НЛТУ України : зб наук.-техн. праць. - Львів : РВВ НЛТУ України. - 2014. - Вип. 24.11. - С. 139-149.

15. Методика определения расчетных величин пожарного риска в зданиях, сооружениях строениях различных классов функциональной пожарной опасности (Приложение к приказу МЧС РФ от 30.06.2009 № 382). - М. : Изд-во МЧС РФ, 2009. - 10 с.

16. Холщевников В.В. Моделирование людских потоков / В.В. Холщевников // Моделирование пожаров и взрывов. - М. : Ассоциация "Пожнаука", 2000. - С. 139-169.

17. Диллон Б. Инженерные методы обеспечения надежности систем : пер. с англ. / Б. Диллон, Ч. Сингх. - М. : Изд-во "Мир", 1984. - 318 с.

18. Hulida E. Mathematical model of the optimization of fire extinguishing time length in the woodworking enterprises' workshops / E. Hulida, O. Koval // Econtechmod. - Lublin; Rzeszow. - 2015. - Vol. 4, № 1. - Pp. 39-43.

19. Системи захисту та безпеки. [Електронний pecypc]. - Доступний http://www.gss.lviv.ua.

20. Сповіщувачі пожежні комбіновані. [Електронний ресурс]. - Доступний 3 http://www.Kolecs.lviv.ua.

21. Автоматика для ворот. [Электронный ресурс]. - Доступный с http://www.alta-pr.all.biz.

Коваль А.М., Гулида Э.Н. Математическая модель определения необходимого количества противопожарных средств в помещениях цехов деревообрабатывающих предприятий

Разработаны математическая модель и методология для определения пожарного риска для помещений цехов деревообрабатывающих предприятий, на основании которых возможно определять мероприятия и необходимые противопожарные средства с учетом допустимого для цеха значения пожарного риска. Для поддержки математической модели пожарного риска, полученной с использованием основных положений теории надежности, разработаны математические модели пожарных рисков основных противопожарных средств, которыми могут оснащаться помешения цехов. Разработанная методология пзволяе ирогнозиреть значение пाя пожарной безопасности объектов защиты и ее последствий для людей и материальных

ценностей, что очень важно для обеспечения возможности быстрого реагирования в случае возникновения пожара.

Ключевые слова: пожар, пожарный риск, ущерб от пожара, расходы на противопожарную зашиту, математическая модель.

Koval O.M., Hulida Ye.M. A Mathematical Model for Determining the Required Number of Firefighting Equipment in the Premises of Shops of Woodworking Companies

The mathematical model and the methodology for determining the fire risk premises for shops at wood processing enterprises are made. On its basis it is possible to determine the necessary measures and fire fighting resources in view of the permissible values for the plant fire risk. To support the mathematical model of fire risk obtained using the main provisions of the reliability theory, mathematical models of fire risks basic fire-fighting equipment, which can be equipped with facilities departments, are built. The developed methodology allows predicting the value of fire risk for the implementation of fire safety facilities of protection and its effects on people and property that is very important to allow for quick response in case of fire.

Keywords: fire, fire risk, fire damage, the cost of fire protection, the mathematical model.

УДК 684.4.04

\section{ФЕНОМЕНОЛОГІЧНА МОДЕЛЬ МІЦНОСТІ КОМПОЗИЦЙНИХ МАТЕРІАЛІВ НА ОСНОВІ ДЕРЕВИНИ}

На основі методів формальної кінетики запропоновано феноменологічну модель міцності композиційних матеріалів на основі деревини. Показано, що багато моделей формальнӧ̈ кінетики створені на основі рівняння Арреніуса. На підставі результатів попередніх дослід

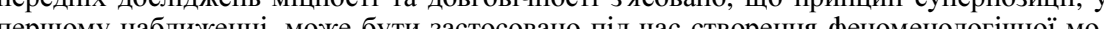
делі, лка враховус вияив модуль пружності. Доведено, що саме нелінійні ефекти у реакції твердих тіл на зовнішні дії призводять до особливостей їхнього деформування і руйнування.

Ключові слова: межа міцності, модуль пружності, довговічність, рівняння Арреніуса.

Актуальність роботи, короткий опис питання. Методи та моделі прогнозування тривалої міцності дають змогу за допомогою обчислювального експерименту отримувати результати, близькі до експериментальних тільки у разі, якщо вони враховують найбільш важливі фактори, що впливають на граничний стан матеріалу під час його експлуатації. Під час тривалої експлуатації композиційні матеріали на основі деревини постійно піддаються термо-вологосиловим навантаженням. Ці зовнішні впливи найчастіше пов'язані як із зовнішнім навантаженням, так і з річними та добовими циклічними змінами температури та вологості навколишнього середовища.

Феноменологічна модель бере за основу поведінку модельованих об'єктів, як результат дії деякого процесу, суть якого загалом приблизно зрозуміла, але у деталях поки ще не з'ясована. При цьому в модель вводять деякі "постійні", що описують специфіку поведінки об'єкта, з конкретизацією цього об'єкта, але без конкретизації точного сенсу самих "постійних". Феноменологічні моделі дуже часто є зручним прогностичним інструментом, оскільки, з одного боку, кількісно пророкують розвиток подій, а з іншого, не потребують точного знання структури та інших особливостей модельованих об'єктів. 
Мета дослідження - розробити феноменологічну модель міцності деталей із композиційних матеріалів на основі деревини під впливом термо-, волого-механічного навантаження.

Методика досліджень. Щоб уявити феноменологічну модель міцності композиційних матеріалів на основі деревини, скористаємося методологією формальної кінетики, яка вивчає залежність швидкості процесу (що відбувається за постійної температури) від різних факторів. Формальна кінетика не пояснює характеру залежностей та детального механізму того, як відбуваються процеси. Процеси вивчають і класифікують на основі кількох принципів, що прийняті за аксіому. До них належить, наприклад, закон діючих мас, який дає змогу визначити швидкість процесу за допомогою молярних концентрацій реагентів [1]. Однак формальні кінетичні рівняння, завдяки простоті, набувають широкого застосування в інженерних розрахунках та кінетичних дослідженнях [2].

Результати досліджень. Оскільки під час побудови моделі міцності розглядаємо області тільки пружних деформацій, то межа міцності та модуль пружності в області пружних деформацій лінійно залежать від величин зовнішнього термо-волого-силового впливу. Тому можна прийняти, що швидкість руйнування в цій області $є$ величина постійна, а сам процес збереження міцності (втрати міцності) вважати аналогом реакції нульового порядку. Причому в області пружних деформацій порядок реакції не змінюється.

Прийнявши такі допущення, можна припустити, що експериментально повинна спостерігатися залежність межі міцності і модуля пружності від температури у вигляді рівняння Арреніуса

$$
k(T)=A e^{-\frac{E_{A}}{R T}},
$$

де: $A$ - передекспоненціальний множник (pre-exponential factor); $E_{A}$ - спостережувана (уявна) енергія активації. Цей закон адекватно описує експериментальні дані багатьох процесів за змін температури в інтервалі менш 50-100 К.

Рівняння Арреніуса - одне 3 найважливіших рівнянь фізичної хімії. У сучасній інтерпретації, це рівняння визначає не тільки температурну залежність коефіцієнта швидкості процесу $k$, наприклад, швидкість хімічної реакції, але й швидкість дифузії, довговічність, період релаксації, параметр руйнування. При цьому у кожному конкретному випадку величини, що входять до цього рівняння, мають різну інтерпретацію [3-8]. Найчастіше значення постійної інтегрування $A$, (предекспоненціальний множника) інтерпретується у вигляді константи за граничних величин, що входять до рівняння змінних, що визначають характер зовнішнього впливу (температури, навантаження, вологості тощо). Причому $A$ $E_{A}-$ константи, що не залежать (або майже не залежать) від температури у досліджуваному діапазоні.

Внаслідок проведених раніше досліджень параметрів міцності стружкових плит і плит МДФ виявлено залежності меж міцності, модулів пружності від температури та вологості, що близькі до лінійної $[9,10]$. Крім того, під час дослідження довговічності цих матеріалів визначено, що взаємний вплив температурно-силового навантаження вносить істотну нелінійність у рівняння їх довговічності [11].
Стосовно нашого випадку визначимо феноменологічну модель міцності у такому вигляді:

$$
\begin{gathered}
\sigma_{W, T}=\sigma_{0} e^{-\frac{\alpha}{W_{e}}} e^{-\beta T_{e}} e^{\gamma \frac{W_{e}}{T_{e}}} ; \\
E_{W, T}=E_{0} e^{-\frac{\delta}{W_{e}}} e^{-\varepsilon T_{e}} e^{\theta \frac{W_{e}}{T_{e}}},
\end{gathered}
$$

де: - фактична, поточна межа міцності, тобто межа міцності за поточної вологості $W(\%)$ та температури $T\left({ }^{\circ} \mathrm{K}\right), \mathrm{MPa} ;-$ постійний коефіцієнт, що дорівнює максимально можливій для певного матеріалу межі міцності, за $W=0, \%$ та $T=0,{ }^{\circ} \mathrm{K}, \mathrm{MPa} ; W_{e}=\frac{W_{m}-W}{W_{m}}-$ ефективна вологість; $W_{m}-$ гранично допустима вологість матеріалу, за якої він володіє достатніми для експлуатації пружними властивостями міцності, \%; $W$ - поточна вологість матеріалу під час експлуатації, \%; $T_{e}=\frac{T_{m}-T}{T_{m}}-$ ефективна температура; $T_{m}-$ гранична температура існування матеріалу, що здатний сприймати зовнішні навантаження, достатні для його експлуатації, ${ }^{\circ} \mathrm{K} ; T$ - поточна температура матеріалу під час експлуатації, ${ }^{\circ} \mathrm{K} ; \alpha$, $\beta, \gamma, \delta, \varepsilon, \theta$ - постійні коефіцієнти; $\alpha, \delta$ - коефіцієнти, що враховують вплив вологості матеріалу на межу міцності і модуль пружності; $\beta, \varepsilon-$ коефіцієнти, що враховують вплив температури матеріалу на межу міцності і модуль пружності; $\gamma, \theta$ - враховують зміну міцнісних властивостей матеріалу за спільної дії вологості й температури, тобто нелінійний характер процесу зміни міцності; $E_{W, T}-$ поточний модуль пружності, $\mathrm{MPa} ; E_{0}$ - постійний коефіцієнт, що дорівнює теоретично максимально можливому для певного матеріалу модулю пружності, за $W=0, \%$ та $T=0,{ }^{\circ} \mathrm{K}, \mathrm{MPa}$.

Результати натурного експерименту. Наприклад, під час проведення випробувань меблевих деталей на чистий згин, модель реалізували таким чином. Випробування проводили на базі стандартної розривної машини моделі Р5 за методикою визначення межі міцності та модуля пружності під час згину згідно зі стандартом ГОСТ 10635-88. Умови проведення випробувань та середні результати чотирьох серій випробувань, у кожній із яких було випробувано по

\begin{tabular}{|c|c|c|c|c|c|c|c|c|}
\hline \multirow[b]{2}{*}{ № } & \multicolumn{4}{|c|}{ Характеристика матеріалу } & \multicolumn{2}{|c|}{ Умова випробувань } & \multicolumn{2}{|c|}{$\overline{\text { Результат випробувань }}$} \\
\hline & $\begin{array}{c}\text { Назва } \\
\text { матері- } \\
\text { алу }\end{array}$ & $\begin{array}{l}\text { Щіль- } \\
\text { ність, } \\
\rho, \text { кг/м }\end{array}$ & $\begin{array}{c}\text { Гранична } \\
\text { температу- } \\
\text { ра, } T_{m},{ }^{0} \mathrm{~K}\end{array}$ & \begin{tabular}{|c|} 
Гранична \\
вологість \\
$W_{m}, \%$
\end{tabular} & $\begin{array}{c}\text { Темпе- } \\
\text { ратура } \\
T,{ }^{6} \mathrm{C}\end{array}$ & $\begin{array}{l}\text { Воло- } \\
\text { гість } \\
W, \%\end{array}$ & $\begin{array}{c}\text { Межа } \\
\text { міцності } \\
{[\sigma], \mathrm{MPa}}\end{array}$ & \begin{tabular}{|c|} 
Модуль \\
пружності \\
$E, \mathrm{MPa}$
\end{tabular} \\
\hline 1 & \multirow{4}{*}{$\begin{array}{c}\text { МДФ } \\
16 \text { мм } \\
\text { Korosten }\end{array}$} & \multirow{4}{*}{820} & \multirow{4}{*}{473} & \multirow{4}{*}{22} & 15 & 7,5 & 39,1 & 4459 \\
\hline 2 & & & & & 80 & 10 & 28,4 & 3261 \\
\hline$J$ & & & & & 25 & 20 & 18,7 & 2100 \\
\hline 4 & & & & & 60 & 12 & 29,6 & 3437 \\
\hline
\end{tabular}
10 зразків, наведено у табл. 1.

Табл. 1. Параметри проведення випробувань

На підставі отриманих під час випробувань даних, розраховано параметри міцності та пружності, які враховують температурно-вологісні умови 
експлуатації виробів 3 плити МДФ товщиною 16 мм, щільністю 820 кг/м³ виробництва Коростенського заводу МДФ (табл. 2).

Табл. 2. Параметри міцності та пружності плит МДФ товщиною 16 мм, цільністю $820 \mathrm{\kappa z} / \mathrm{M}^{3}$

\begin{tabular}{|c|c|c|c|}
\hline \multicolumn{3}{|c|}{ щиільністю $\mathbf{8 2 0} \mathbf{~} \mathbf{2} / \mathbf{M}$} \\
\hline Параметр міцності & \multicolumn{2}{|c|}{ Параметр пружності } \\
\hline$\sigma_{0}$, МПа & 56,1 & $E_{0}$, МПа & 8413 \\
\hline$\alpha$ & $-3,47$ & $\delta$ & $-3,85$ \\
\hline$\beta$ & $-0,81$ & $\varepsilon$ & $-0,94$ \\
\hline$\gamma$ & 3,87 & $\theta$ & 4,07 \\
\hline
\end{tabular}

Використовуючи знайдені параметри міцності, за допомогою формул (1), (2) розрахуємо яка має буті розрахункова межа міцності та модуль пружності деталі, що працює на чистий згін за зміни температури експлуатації у межах від 0 до $100{ }^{0} \mathrm{C}$ та вологості матеріалу від $0 \%$ до $20 \%$.

На рис. наведено результати розрахунків межі міцності та модуля пружності залежно від температурно-вологісних умов.
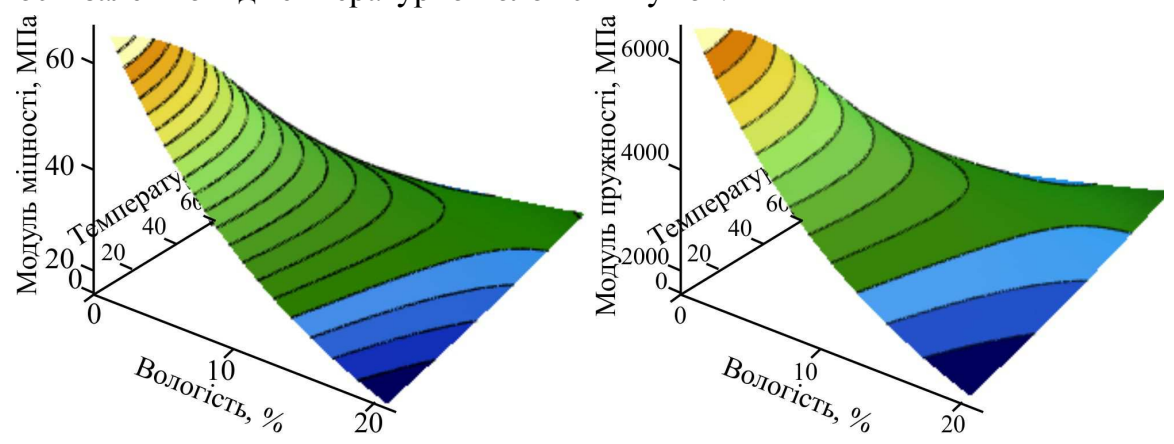

Рис. Результати розрахунків межі міцності та модуля пружності залежно від температурно-вологісного режиму експлуатації

Висновки. Таким чином, використання моделі дає змогу прогнозувати межу міцності та модуль пружності деталей із деревно-композиційних матеріалів за конкретних умов їх експлуатації.

\section{Література}

1. Полак Л.С. Неравновесная химическая кинетика и ее применение / Л.С. Полак. - М. : Изд-во "Наука", 1979. - 248 с.

2. Регель В.Р. Кинетическая природа прочности твердых тел / В.Р. Регель, А.И. Слуцкер, Э.Е. Томошевский. - М. : Изд-во "Наука", 1979. - 560 с.

3. Ратнер С.Б. Физическая механика пластмасс. Как прогнозируют работоспособность? / 3. Ратнер С.Б. Физическая механика пластмасс. Как пр
С.Б. Ратнер, В.П. Ярцев. - М. : Изд-во "Химия", 1992. - 320 с.

4. Плиты древесностружечные. Методы определения предела прочности и модуля упругости при изгибе. ГОСТ 10635-88. - М. : Изд-во "Стандартов", 1989. - 7 с.

5. Петров В.А. Физические основы прогнозирования долговечности конструкционных катериалов / В А. Петров, А. Я. Башкарев, В.И. Веттергень. - СПб. : Изд-во "Политехника", 1993. $-475 \mathrm{c}$.

6. Штиллер В. Уравнение Аррениуса и неравновесная кинетика : пер. с англ. / В. Штиллер. М. : Изд-во "Мир". - 176 с.

7. Бартенев Г.М. Физика и механика полимеров / Г.М. Бартенев, Ю.В. Зеленев. - М. : Издво "Высш. шк.", 1983. - 391 с.
8. Абаимов С.Г. Статистическая физика сложных систем: От фракталов до скейлингповедения. - М. : Кн. дом "Либроком", 2013. - 392 с.

9. Пригожин И. Современная термодинамика. От тепловых двигателей до диссипативных структур : пер. с англ. / И. Пригожин, Д. Кондепуди. - М. : Изд-во "Мир", 2009. - 461 с.

10. Bekhta P. (2007) Bending strength and modulus of elasticity of particleboards at various temperatures / P. Bekhta, R. Marutzky // Holz Roh-Werkst 65. - Pp. 163-165.

11. Bekhta P. (2009) Effect of relative humidity on some physical and mechanical properties of different types of fiberboard / P. Bekhta, P. Niemz // Eur. J. Wood Prod 67. - Pp. 339-349.

12. Кульман С.М. Нелінійні єфекти деформування і руйнування композиційних матеріалів на основі деревини / С.М. Кульман // Науковий вісник НУБіП України : зб. наук. праць. - Сер.: Лісівництво і декоративне садівництво. - К. : Вид-во НУБіП України. - 2011. - Вип. 164, ч. 1. C. $250-255$

Кульман С.Н. Феноменологическая модель прочности композиционных материалов на основе древесины

На основе методов формальной кинетики предложена феноменологическая модель прочности композиционных материалов на основе древесины. Показано, что многие модели формальной кинетики созданы на основе уравнения А.рениуса. На основаие мезулор нии реультагов нредду भто принци суп нии феноменолог ности на предел прочности и модуль упругости. Показано, что именно нелинейные эффекты в реакции твердых тел на внешние воздействия приводят к особенностям их деформирования и разрушения.

Ключевые слова: предел прочности, модуль упругости, долговечность, уравнение Аррениуса.

Kulman S.M. The Phenomenological Model of the Strength of Composite

\section{Materials Based on Wood}

Based on the methods of formal kinetics, a phenomenological model of strength composite materials based on wood is proposed. It has been shown that many of the formal kinetics models are based on the Arrhenius equation. Based on the results of the previous studies of strength and durability it is shown that the principle of superposition, to a first approximation, strength and ducition can be und in crets of temperature and humidity or the .

Keywords: tensile strength, elastic modulus, durability, composite material.

УДК 621.187:142

Пров. наук. співроб. Р.О. Навродська, канд. техн. наукІнститут технічної теплофізики НАН Украӥни, м. Київ

ЗАПОБІГАННЯ КОНДЕНСАТОУТВОРЕННЮ У ДИМОВИХ ТРУБАХ

\section{ЗА ЗНИЖЕННЯ ТЕПЛОВОГО НАВАНТАЖЕННЯ КОТЕЛЕНЬ}

Проаналізовано тепловологісний стан у димових трубах комунальних котелень у разі застосування сучасних теплоутилізаційних технологій зі системами антикорозійного захисту газовідвідних трактів за умов зменшення відносно проектних теплових навантажень цих котелень. Наведено результати досліджень щодо використання у теплоутилізаційних схемах таких теплових методів запобігання конденсатоутворенню у газовідвідних трактах як: байпасування частини відхідних газів котла повз теплоутилізатор, підсушування охолоджених у теплоутилізаторі газів у поверхневому теплообміннику та теплоізоляція корпусу димової труби. Визначено безпечні для експлуатації димових труб різного типу режими роботи котелень та основні характеристики вказаних систем захибу.

Ключові слова: опалювальні котельні установки, теплоутилізація, димові труби різного типу, теплове навантаження, конденсатоутворення, системи теплового захисту.

4. Інформаційні технологї галузі 